\section{$\underset{\substack{\text { hommes } \\ \text { \& migrations }}}{ }$}

\section{Hommes \& migrations}

Revue française de référence sur les dynamiques

migratoires

$1331 \mid 2020$

Femmes engagées

\title{
Laakri Chérifi, Les chanteuses kabyles. Graines de la douleur
}

Paris, L'Harmattan, 2020, 276 p., $27 €$.

\section{Mustapha Harzoune}

\section{(2) OpenEdition}

Journals

Édition électronique

URL : https://journals.openedition.org/hommesmigrations/11867

DOI : 10.4000/hommesmigrations. 11867

ISSN : 2262-3353

Éditeur

Musée national de l'histoire de l'immigration

Édition imprimée

Date de publication : 17 novembre 2020

Pagination : 188

ISBN : 978-2-919040-52-0

ISSN : 1142-852X

Référence électronique

Mustapha Harzoune, "Laakri Chérifi, Les chanteuses kabyles. Graines de la douleur 》, Hommes \&

migrations [En ligne], 1331 | 2020, mis en ligne le 01 novembre 2020, consulté le 04 janvier 2023. URL :

http://journals.openedition.org/hommesmigrations/11867; DOl : https://doi.org/10.4000/

hommesmigrations. 11867 
Les chanteuses kabyles. Graines de la douleur

Laakri Chérifi, Paris,

L'Harmattan, 2020, 276 p., $27 €$.

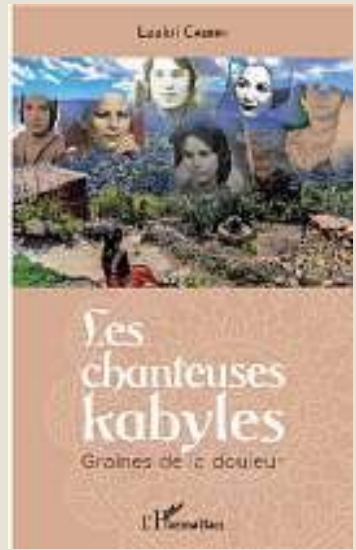

H'nifa, Chérifa, Nouara, Taos Amrouche, Malika Domrane, Djohra Abouda ou Massa Bouchafa forment trois générations d'artistes femmes qui, depuis les années 1940, ont bravé les interdits et le code "paroxystique de l'honneur» de la société kabyle. Trois générations qui ont porté un héritage et qui, dans le même mouvement, ont su le renouveler, le moderniser: par la radio et les enregistrements, par les thèmes traités et les formes vocales, musicales et orchestrales, par des prestations publiques, autrement dit devant des hommes. Grâce à ces artistes, les voix des femmes kabyles sont sorties du cadre codifié des fêtes de village pour partir à la rencontre du monde. Comme le précise avec emphase le sous-titre, elles ont chanté la douleur et d'abord l'universelle, "suprématie des hommes», cet "ordre social primitif et brutal, dans lequel la femme kabyle était écrasée, assujettie et réduite à néant». Les douleurs de l'exil aussi et de l'infidélité de celui qui part: «Étourneau voyageur / Suis-le en bateau / Dis-lui pourquoi m'a-t-il trahi. » L'exil c'est aussi celui de ces femmes qui, parties à Alger ou à Paris, ont transgressé les règles. Il devient bannissement,

déracinement, «chance» qui s'est enfuie à jamais: "Tura ifuk zzhu / Maintenant les joies sont finies» chante Chérifa quand pour Nouara: "L'exil est un fardeau / Ma solitude aussi / la mauvaise compagnie dont je suis affublée me dégoûte.»

Les pionnières ont perpétué les modes traditionnels et une poésie d'édification. Ici, la religion, les valeurs et l'éthique de comportements kabyles sont rappelées, convoquées, implorées. On en appelle à Dieu, au Livre et à une foultitude de saints locaux - culte peu apprécié des tenants d'un islam rigoriste qui laisse peu de place au sacré. Les nouveautés thématiques et de formes sont venues progressivement. Ces chanteuses se sont comme «projeter dans l'avenir sans se déraciner». Pourtant, le milieu artistique, largement masculin, n'a pas fait toute sa place à l'œuvre de ces femmes, renvoyé au «folklore», à un «genre mineur» par les chefs d'orchestre de l'époque. En contrepoint, l'auteure rappelle l'influence d'une Amalia Rodriguez.

Par la chanson, ces femmes traduisaient leurs "états d'âme»: les «ighelban» (tourments), «l'hif» (misère), « lxiq» (mal d'être), l'abandon, le rejet et le désordre social. Car elles ont aussi porté les souffrances du groupe dans des chants de guerre ou nationalistes, des chants où elles exprimèrent les horreurs endurées par les femmes elles-mêmes. Chants aussi du «désabusement» «face à l'indifférence de l'État quant [au] passé de militantes» des femmes. Douleurs enfin d'une indépendance vécue par la Kabylie «Comme une spoliation d'une victoire à laquelle elle avait largement contribuée»: "Finie la peur, finies les balles et les bombes / Mais notre misère est toujours la même / Quiconque nous déteste / Nous pose le pied sur le ventre et nous écrase. »

S'inspirant des travaux de Youcef Nacib, Mehenna Mahfoufi ou Tassadit Yacine, l'auteure accompagne ses courtes biographies d'extraits bilingues de chanson. Elle replace ce répertoire féminin dans le patrimoine pluriséculaire et l'histoire moderne des littératures kabyles. Dommage que l'éditeur n'ait pas fait son travail (pour un livre plutôt coûteux), laissant le lecteur se dépatouiller avec les fautes d'orthographe, les répétions, les transcriptions aléatoires, sans parler de la couverture... Reste que ce livre offre une utile mise en perspective d'une expérience artistique d'hommes ET de femmes ballottés par l'Histoire encore et toujours réfractaires, vivants, positifs. Pour ces femmes kabyles, dont on ne dira jamais assez le courage - car la musique reste encore "une activité dépréciative»-, le chant est un espace d'énonciation. Énonciation d'une société dont elles portent alors «l'image idéal de soi que forme le groupe»; espace d'expression individuelle, irruption du «je», le chant devient alors l'espace de l'exil, mais aussi espace thérapeutique, exutoire. Un espace de contestation.

M. H. 